noch nicht entscheiden, vielleicht ist eine siebentägige Periode angedeutet; einige Versuche Ende Februar den Stern eine ganze Nacht zu verfolgen, scheiterten an den ungünstigen Witterungsverhältnissen.

$\mathrm{Da}$ mir jetzt (in Gotha) die weitere Verfolgung des Sterns unmöglich ist, möchte ich meine Beobachtungen mit allem Vorbehalt, welchen angesichts der Schwierigkeit der Messungen der Zweifel an der Realität der Resultate fordert, bekannt geben und den Stern zur Beobachtung an geeig. neten Instrumenten empfehlen. Vielleicht werden auch Meridianbeobachter der Sache gelegentlich der Kulminationen von $\alpha$ Ursae min. einige Beachtung schenken.

Gotha, 1903 Juni 2.

E. Fost.

Aufsuchungsephemeride des Fayeschen Kometen.

$12^{\text {h }}$ M. Z. Berlin.

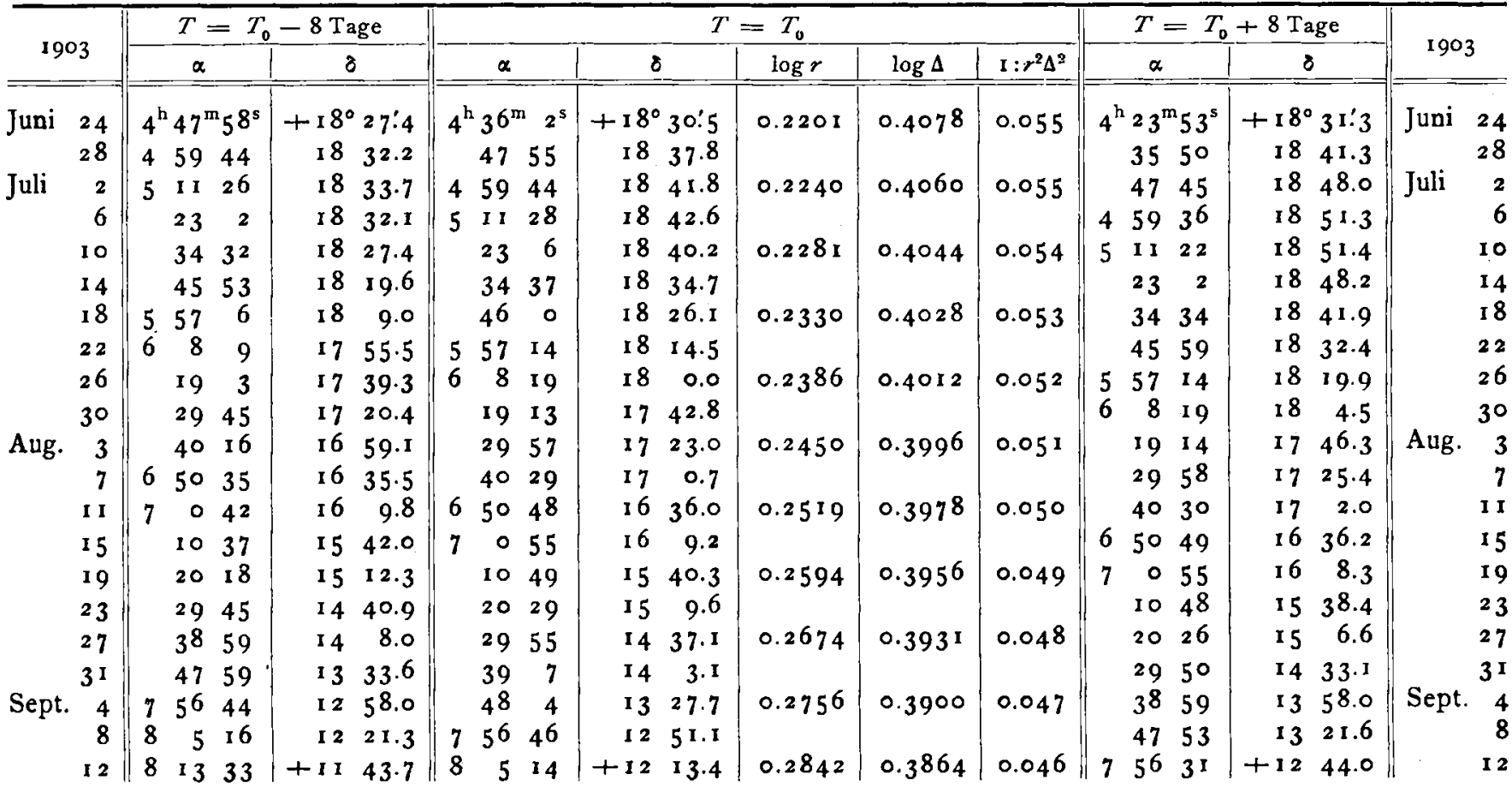

Die Ephemeride ist mit Hülfe des A.N. I6r.32I publizierten Elementensystems $\left(T_{0}=1903\right.$ Juni 3.64 M.Z. Berlin) gerechnet. Was die Sicherheit der Elemente und die Aussichten für die Wiederauffindung betrifft, so wird auf die citierte Stelle verwiesen.

Kiel, Bureau der Astr. Nachr., Juni 1903.

Elis Strömgren.

\title{
Beobachtungen des Planeten (83) Beatrix
}

am 6.zölligen Steinheilschen Refraktor der Sternwarte Pola der k. u. k. Kriegs.Marine.

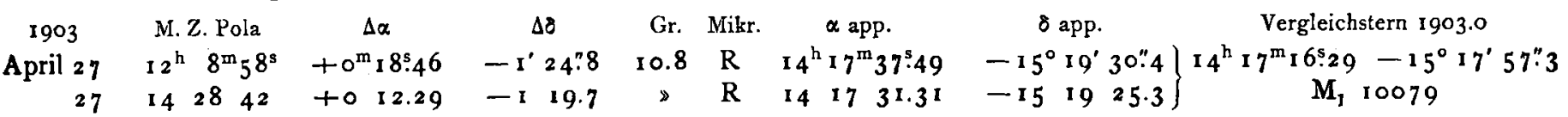

Erste Beobachtung sicher, zweite Beobachtung wegen Eintretens leichter Bewölkung unsicher.

Beobachter k. u. k. Linienschiffsfähnrich Wilhelm Linhart.

Pola, I 903 Mai is.

Der Vorstand: $K$. Koss.

Planet (483) [1902 Hण] ist mit dem nur einmal beobachteten Planeten $1896 \mathrm{CP}$ identisch. $A$. Berberich.

Inhalt zu Nr. 3876 , A. Abetti. Asteroidi osservati ad Arcetri nel 1902. 177. - H. Osten. Bahnelemente des Planeten 1903 LC. 187. - E. Fost. Über eine vermutliche Veränderlichkeit des Begleiters von $\alpha$ Ursae minoris. 189. - E. Strömgren. Aufsuchungsephemeride des Fayeschen Kometen. 191. - K. Koss. Beobachtungen des Planeten (83) Beatrix. 191. - A. Berberich. Planet (483) [1902 HU]. I9I. 